\title{
Development of Thermal Protection Materials for Future Mars Entry, Descent and Landing Systems
}

\author{
Alan M. Cassell ${ }^{1}$, Robin A.S. Beck ${ }^{3}$, James O. Arnold ${ }^{4}$, Helen Hwang ${ }^{5}$, and Michael J. Wright ${ }^{6}$ \\ NASA Ames Research Center, Moffett Field, CA 94035 \\ Christine E. Szalai ${ }^{2}$ \\ Jet Propulsion Laboratory, 4800 Oak Grove Drive, Pasadena, CA 91109 \\ Max Blosser ${ }^{7}$ and Carl C. Poteet ${ }^{8}$ \\ Langley Research Center, Hampton, VA 23681
}

\begin{abstract}
Entry Systems will play a crucial role as NASA develops the technologies required for Human Mars Exploration. The Exploration Technology Development Program Office established the Entry, Descent and Landing (EDL) Technology Development Project to develop Thermal Protection System (TPS) materials for insertion into future Mars Entry Systems. An assessment of current entry system technologies identified significant opportunity to improve the current state of the art in thermal protection materials in order to enable landing of heavy mass $(40 \mathrm{mT})$ payloads. To accomplish this goal, the EDL Project has outlined a framework to define, develop and model the thermal protection system material concepts required to allow for the human exploration of Mars via aerocapture followed by entry. Two primary classes of ablative materials are being developed: rigid and flexible. The rigid ablatives will be applied to the acreage of a 10x30 $\mathrm{m}$ rigid mid L/D Aeroshell to endure the dual pulse heating (peak $\sim 500 \mathrm{~W} / \mathrm{cm}^{2}$ ). Likewise, flexible ablative materials are being developed for 20-30 m diameter deployable aerodynamic decelerator entry systems that could endure dual pulse heating (peak $\sim 120 \mathrm{~W} / \mathrm{cm}^{2}$ ). A technology Roadmap is presented that will be used for facilitating the maturation of both the rigid and flexible ablative materials through application of decision metrics (requirements, key performance parameters, TRL definitions, and evaluation criteria) used to assess and advance the various candidate TPS material technologies.
\end{abstract}

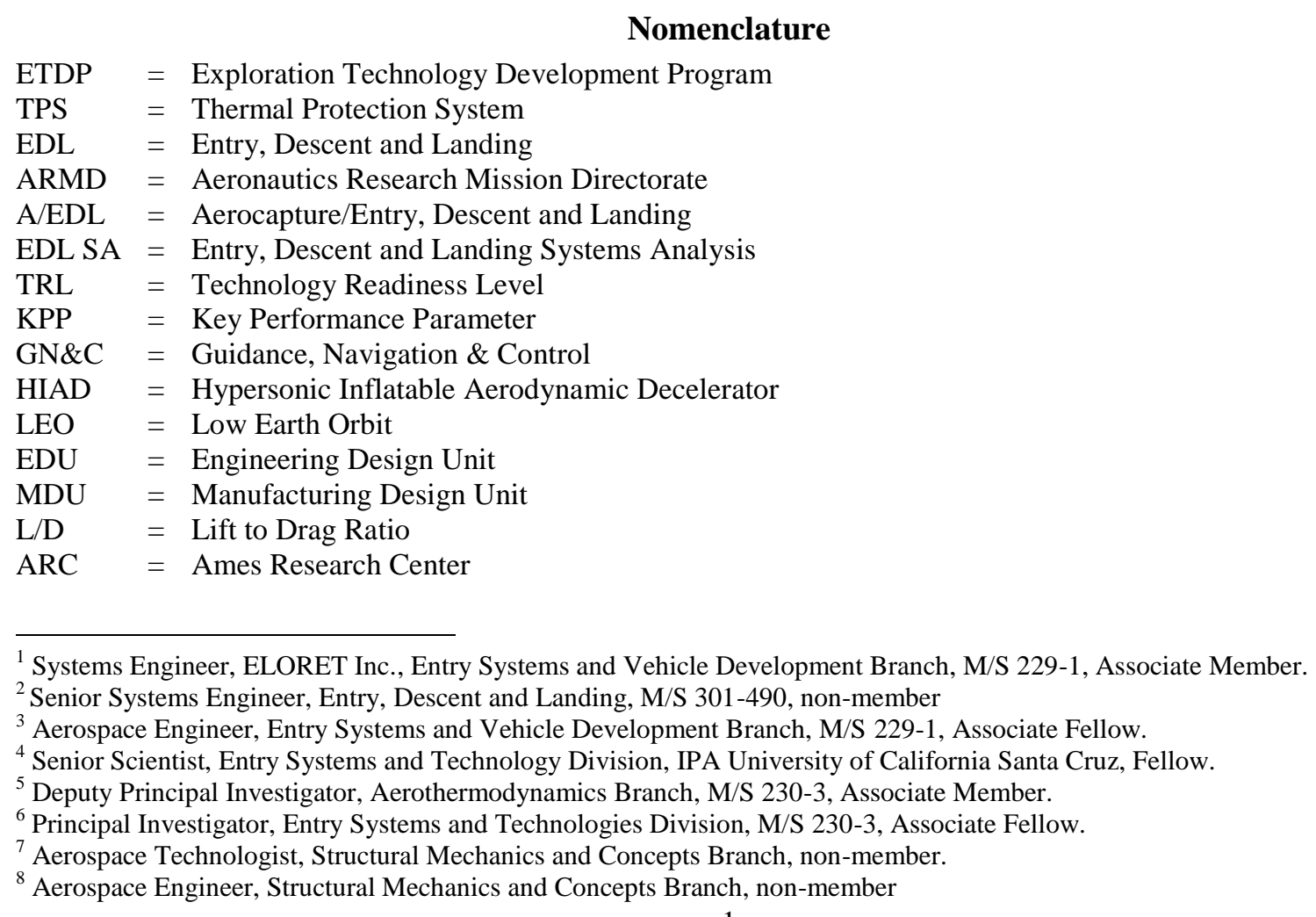

American Institute of Aeronautics and Astronautics 
$\begin{array}{ll}\text { JSC } & =\text { Johnson Space Center } \\ \text { LaRC } & =\text { Langley Research Center } \\ \text { DoD } & =\text { Department of Defense }\end{array}$

\section{Introduction}

The NASA Exploration roadmap calls for human exploration of Mars beginning in the decade of the 2030s, with precursor missions to LEO and the Moon in preceding decades. While the technologies for LEO and Lunar return to Earth are reasonably mature and are under further development within Constellation, the necessary technologies for landing astronauts and exploration class payloads on the surface of Mars do not exist today. The only proven EDL architecture for Mars entry is based on Viking heritage, with extensions for Mars Science Laboratory (MSL). However, this architecture is fundamentally limited to landed masses of less than 2 metric tons, and cannot meet landed elevation and landing precision requirements for larger class exploration missions. The Design Reference Mission as defined by the Entry, Descent and Landing Systems Analysis (EDL SA) team for Mars Missions details potential EDL Systems to deliver multiple 40 metric ton payloads to the surface of Mars in support of Exploration Class missions, in-situ resource utilization, and large scale Exploration. ${ }^{1}$ Previous technology roadmaps have demonstrated that the current Technology Readiness Level (TRL) of the necessary EDL components is so low that immediate technology development is required to support this timeline. ${ }^{2}$ Even if the need date of the technologies were to slip, low to mid TRL technology development is still a high priority, because of the long lead times of the required elements. In both the hypersonic and supersonic stages of EDL there are few proposed technology candidates, and at the current level of fidelity it is not known whether any will be scalable to exploration class missions. The objective of the EDL Exploration Class Missions Project is the development of applicable technologies to a readiness level of TRL 6 for specific Exploration Class Missions. The vision for the Entry, Descent, and Landing Technology Development Project (EDL TDP) is to develop EDL technologies for Exploration Class Missions, including new materials required to survive aerocapture to orbit, long stay on orbit followed by direct entry, supersonic retro-propulsion to control the later stages of entry, and improvement and/or creation of the analytical tools required to predict the environments and vehicle response. A project element under the EDL TDP was created to develop the thermal protection system (TPS) materials for the next generation of Mars Entry vehicles.

The requirements for Aerocapture, Entry Descent and Landing (A/EDL) are under development by the Mars EDL SA project, which is funded by several NASA Mission Directorates. They have developed nine different A/EDL scenarios. Several of these scenarios require the use of innovative ablative TPS to survive the environments. The EDL TDP TPS Element is working to develop lightweight robust rigid ablators for a 10-m diameter, 30-m length mid lift-to-drag ratio (L/D) aeroshell that will be exposed to two heating pulses; the first during aerocapture, and the second during entry. The Element is also developing flexible ablative materials for a 23-m diameter deployable or inflatable aeroshell for hypersonic aerocapture, identified as a key technology investment area by the EDL SA. Conventional flexible material systems may not be able to withstand the high heating rates that ablatives are designed to endure.

In order to plan these TPS efforts effectively, an extensive road mapping task has been undertaken. It involves determination of the basic approach to materials development, describing the specific gates required to achieve the NASA TRLs, developing success criteria or Key Performance Parameters (KPPs) that must be met during the materials development, laying out the project flows, and finally developing the schedules required to mature advanced materials concepts for flight implementation. The following sections will describe the EDL TDP project, the TPS Element of the project and the development of the roadmaps for TPS delivery to future A/EDL demonstration flagship missions. 


\section{Entry, Descent and Landing Technology Development Project Overview}

Figure 1 illustrates notional EDL system architectures that were studied by the EDL SA team. Each architecture contains a sequence of events and methods for delivering a human-scale payload to the surface of Mars using technologies that have never been flown or demonstrated at the required scale. Architecture 1 was adopted from previous studies as part of the Mars Design Reference Architecture 5.0. ${ }^{2}$ This architecture consists of a rigid, mid L/D 10-m diameter by 30-m length aeroshell used for aerocapture and hypersonic deceleration, followed by a supersonic retro-propulsion (SRP) phase ending at terminal descent. Architecture 2 consists of a 23-m deployable or inflatable aeroshell used for both aerocapture and hypersonic deceleration, also followed by an SRP phase. The EDL SA team evaluated each of the architectures and determined that many of the technologies required for these architectures were either in their infancy or non-existent. The EDL TDP was formed to develop some of the required technologies.

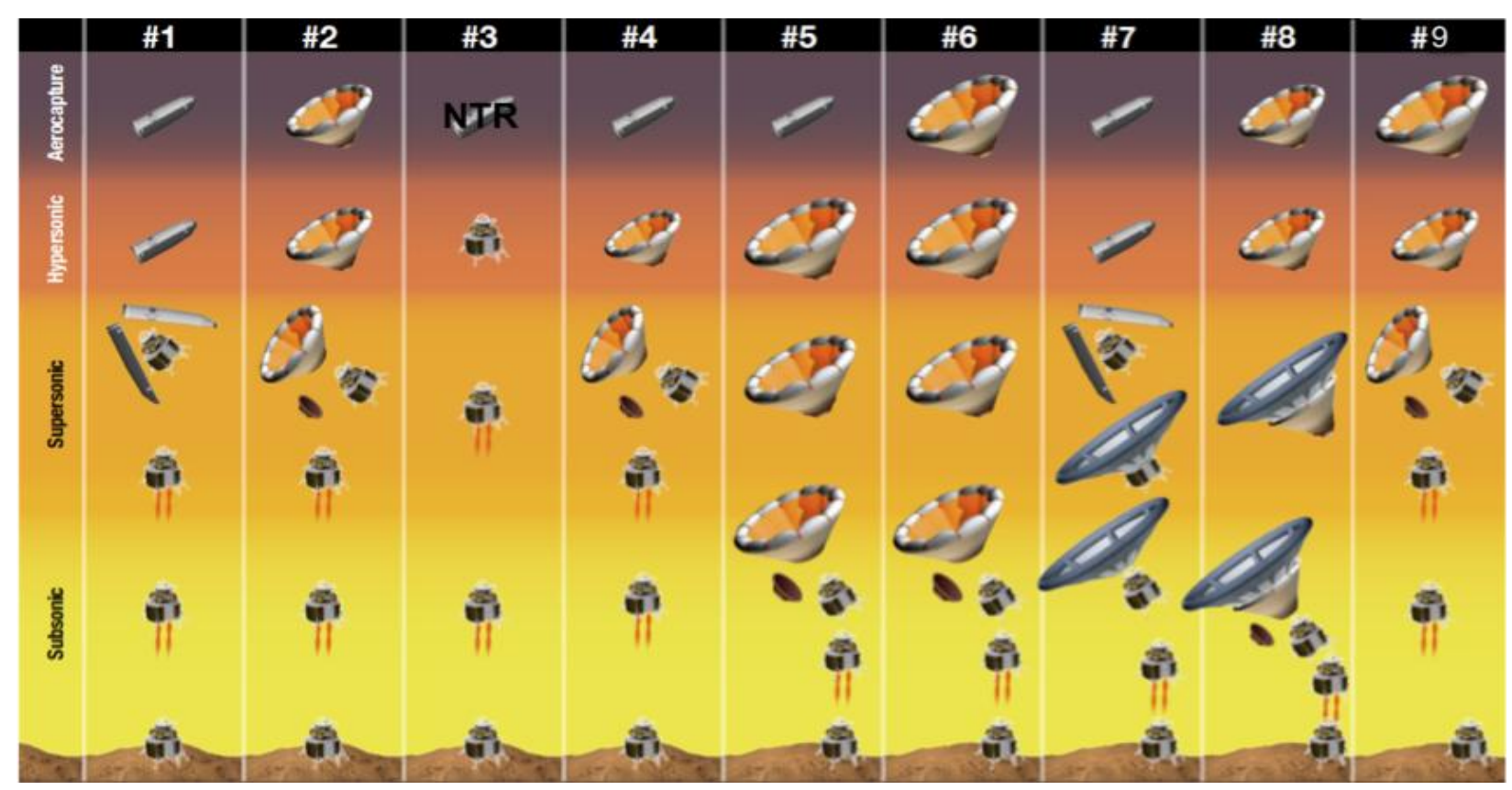

Figure 1- Candidate architectures under consideration by the Entry, Descent and Landing Systems Analysis team for landing heavy mass payloads on the surface of Mars.

The EDL TDP is divided into three elements: Thermal Protection Systems (TPS), Supersonic Retropropulsion (SRP), and Models and Tools Development (MAT).

The goal of the TPS Element is to develop TPS materials and systems whose performance meet the initial requirements derived from the EDL SA architectures. The Element will define, develop, and model the TPS material concepts required to allow for the human exploration of Mars via aerocapture followed by entry. The TPS Element will focus on developing material concepts for the entire acreage of the $10 \times 30 \mathrm{~m}$ rigid Aeroshell entry system capable of enduring dual pulse heating (peak $\sim 500 \mathrm{~W} / \mathrm{cm}^{2}$ ), as well as a $23 \mathrm{~m}$ diameter deployable entry system capable of withstanding $\sim 120 \mathrm{~W} / \mathrm{cm}^{2}$ peak heating experienced during aerocapture and subsequent entry.

The goal of the SRP Element is to develop retro-propulsion systems that support the EDL SA architectures. Specifically, this element will demonstrate SRP as a viable technology for delivering high mass payloads to Mars and establish SRP expertise within NASA. The supporting disciplines (aero/aerothermal, Guidance, Navigation, \& Control (GN\&C)) and center collaboration, which are strong from past experience, will be tailored and integrated to develop the SRP expertise. 
The goal of the MAT Element is to develop computational models for aeroshell design and development which support Exploration Class Systems. The element will implement, calibrate and validate state of the art enhanced engineering and high fidelity modeling capabilities to enable large mass rigid and flexible aeroshell entry vehicle design for the human exploration of Mars. MAT will enable modeling capabilities for design of fixed/flexible entry vehicles through radiation, turbulence modeling, fluid structure interactions that are coupled with the ablation response model. Furthermore, ground testing methods and instrumentation techniques, rapid assessment, and probabilistic design will also be developed. 


\section{Thermal Protection System Element Overview}

The EDL TDP TPS Element consists of three main tasks: Systems Engineering, Rigid TPS Materials Development, and Flexible/Deployable TPS Materials Development. The Systems Engineering task integrates the requirements from the EDL SA, develops the technology development framework and performs trade studies on TPS materials for both the rigid and flexible/deployable concepts. This task has also established the roadmaps for the materials development.

The Rigid Ablators development task is developing the lightweight, robust advanced TPS systems required for dual heat pulse aerocapture and entry for the rigid mid L/D Aeroshell. Most of materials for this task will be codeveloped and improved by an iterative feedback loop with industry. Thermal response analysis techniques will be upgraded to include the effects of multiple layers of ablating and decomposing materials along with the capability for the surface material to change as layers are removed.

The Flexible/Deployable materials development task is developing ablative flexible material concepts for use on the 23-m diameter deployable aeroshell capable of performing in the critical Aerocapture phase. To date, most of the materials under evaluation are being developed by NASA in-house material scientists.

\section{A. Entry, Descent and Landing Architecture Assumptions}

The requirements for the TPS technology Roadmap were derived from the current EDL architectures being considered by the EDL SA team. Figure 1 depicts the nine architectures currently under study. Two of the architectures (1 and 7), make use of a dual-use capable mid L/D Aeroshell. There are also two architectures (2 and 8) that utilize a dual-use capable 23-m diameter hypersonic inflatable (or deployable) aerodynamic decelerator (HIAD). Initial assumptions made by the EDL SA team were then used to formulate Mars aerocapture and entry trajectories from which the requisite dual-pulse aerothermal entry environment requirements were derived for the 23 $\mathrm{m}$ diameter HIAD and rigid mid L/D aeroshell (figure 2). These performance requirements are detailed below for the two primary classes of ablative materials under consideration.
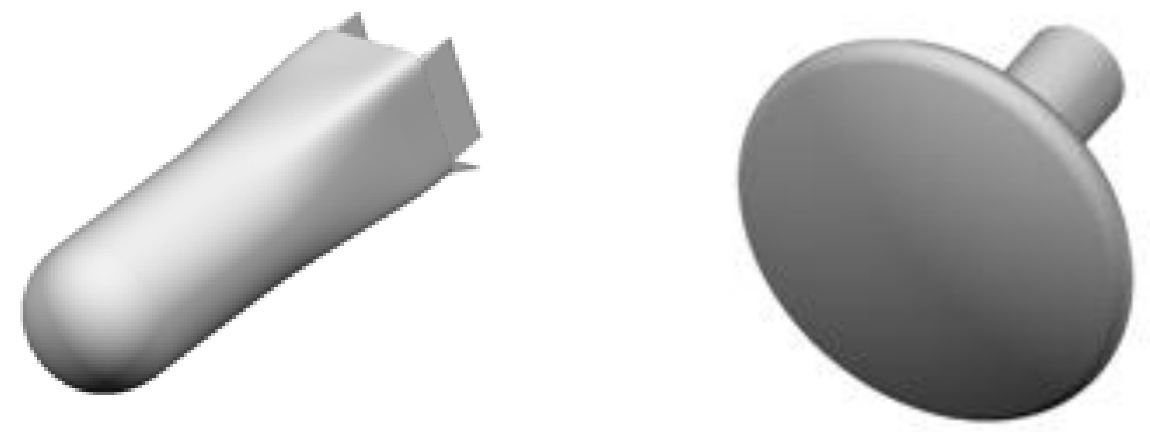

Figure 2: Rigid mid L/D Aeroshell Entry Vehicle (left) and Hypersonic Inflatable Aerodynamic Decelerator (right) Concepts for Heavy Mass Missions to Mars (not to scale). 


\section{B. Rigid Ablator Requirements - Rigid Ablators for 10 x 30 m Mid L/D Aeroshell}

The rigid Aeroshell TPS concept is required to survive two heating pulses, the first during aerocapture into Mars orbit, and the second during entry into the Martian atmosphere. In addition, the rigid Aeroshell TPS concept is required to minimize TPS mass in order to maximize payload mass. The aerocapture and entry phases could be separated by as much as two years. The mid L/D Aeroshell has three general regions of thermal heating: the backshell (lowest heating), nose cone (medium heating), and heatshield (highest heating). Figure 2 (left panel) depicts the rigid aeroshell concept. Primary development focus will be directed towards the heatshield, or windward side of the mid L/D Aeroshell, where the highest heating rates and thermal loads will occur. Analysis has shown significant mass savings could be derived from advancements in next-generation ablative TPS concepts.

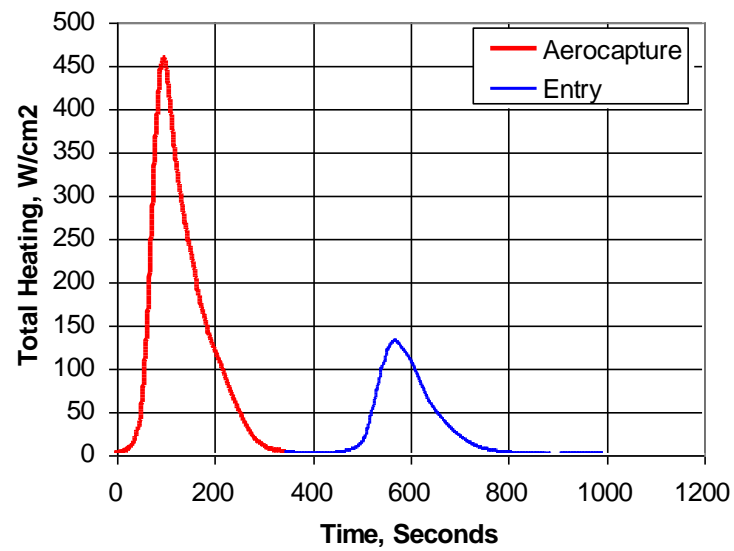

Figure 3- Maximum heat pulse prediction for aerocapture and entry utilizing the mid L/D Aeroshell for a representative trajectory.

\begin{tabular}{|l|c|}
\hline Aerothermal Entry Environments-Rigid & Value \\
\hline Peak Total Heat Rate (Aerocapture) & $450 \mathrm{~W} / \mathrm{cm}^{2}$ \\
\hline Peak Aerocapture Heat Rate (Convection) & $400 \mathrm{~W} / \mathrm{cm}^{2}$ \\
\hline Peak Aerocapture Heat Rate (Radiation) & $130 \mathrm{~W} / \mathrm{cm}^{2}$ \\
\hline Peak Heat Rate (Entry) & $130 \mathrm{~W} / \mathrm{cm}^{2}$ \\
\hline Peak Entry Heat Rate (Convection) & $130 \mathrm{~W} / \mathrm{cm}^{2}$ \\
\hline Peak Entry Heat Rate (Radiation) & $20 \mathrm{~W} / \mathrm{cm}^{2}$ \\
\hline Total Heat Load (Aerocapture + Entry) & $80 \mathrm{~kJ} / \mathrm{cm}^{2}$ \\
\hline Heat Load (Aerocapture) & $55 \mathrm{~kJ} / \mathrm{cm}^{2}$ \\
\hline Heat Load (Entry) & $25 \mathrm{~kJ} / \mathrm{cm}^{2}$ \\
\hline Peak Pressure (Aerocapture) & $45 \mathrm{kPa}$ \\
\hline Peak Pressure (Entry) & $25 \mathrm{kPa}$ \\
\hline Peak Shear Force (Aerocapture) & $700 \mathrm{~Pa}$ \\
\hline Peak Shear Force (Entry) & $300 \mathrm{~Pa}$ \\
\hline
\end{tabular}

Table 1- Summary of aerothermal environments predicted for the rigid mid L/D Aeroshell concept.

The concepts being considered include multilayer (e.g., ablator over insulator or ablator over ablator), and improved higher performance, light weight materials. The heat flux profiles (heat flux as a function of time, fully margined) for both maneuvers are shown in Figure 3. The corresponding summary of peak aerothermal environments is displayed in Table 1.

Although the environments shown in Table 1 are not too severe, it is the total heat load which dictates the sizing of the TPS material (maintenance of bondline temperature requirement). Existing materials such as Phenolic Impregnated Carbon Ablator (PICA), currently the forebody heatshield for the Mars Science Laboratory, could be 
designed to the requirements, but at a high mass penalty. Any mass savings on the Aeroshell translates into more delivered payload mass, and thus alternative TPS material architectures are being pursued to enable larger payload mass fraction to the surface. As an example, the EDL SA explored the use of a dual-layer ablator over insulator concept, and performed TPS sizing studies to determine the mass savings benefit. Taking into account material response and thermal soak back for the dual-pulse entry, sizing of PICA over Shuttle Orbiter derived insulating tiles showed a total mass of 7.3 metric tons, a savings of 4 metric tons compared to a solution of PICA only (11.3 metric tons), a 35\% reduction in TPS mass. ${ }^{3}$ Concepts similar to the ablator over insulator, such as mid-density ablator over low density ablator also show similar mass savings potential. However, many other factors which are outlined below will need to be well understood in order to properly design, test and manufacture such systems.

\section{Requirements - Flexible Ablators for $\mathbf{2 3}$ m diameter Inflatable Aerodynamic Decelerators}

A potentially more mass efficient, but less developed, method for Mars EDL is application of a deployable aeroshell decelerator system. Expected to be much lighter than the rigid aeroshell solution, the deployable aeroshell system requires the use of flexible TPS materials. With the deployable system, the spacecraft would deploy a large heatshield (via inflation or other mechanical means) prior to the aerocapture maneuver, as shown in Figure 2 (right panel). Figure 4 shows the maximum heat pulse experienced on a $23 \mathrm{~m}$ diameter HIAD for both aerocapture and entry (margined). The corresponding summary of entry environment parameters is shown in Table 2. Conventional insulating flexible materials cannot withstand the $>100 \mathrm{~W} / \mathrm{cm}^{2}$ heat flux expected on the $23-\mathrm{m}$ diameter geometry. This requirement is the impetus for the development of flexible ablative materials.

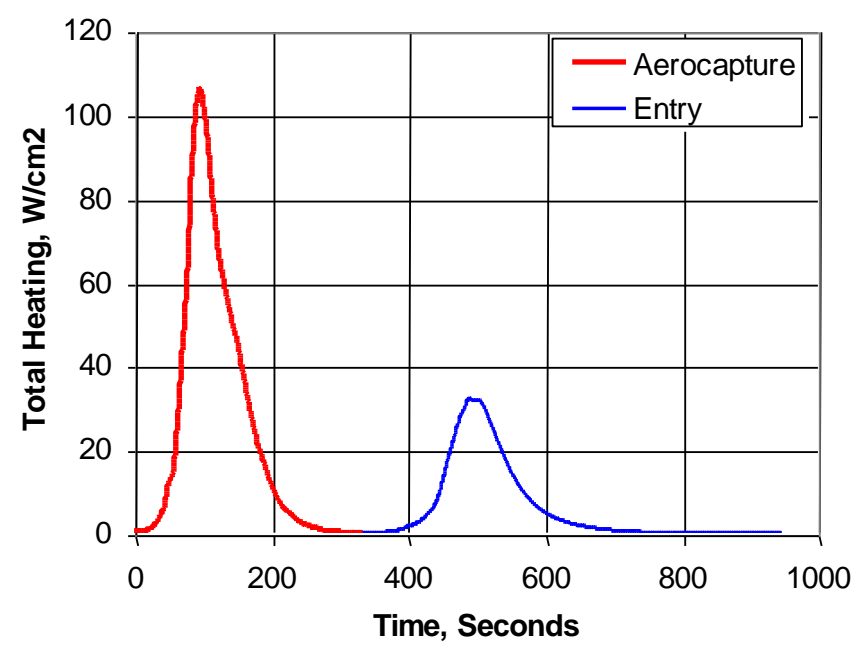

Figure 4- Maximum heat pulse prediction for aerocapture and entry utilizing the $23 \mathrm{~m}$ diameter HIAD entry vehicle concept.

\begin{tabular}{|l|c|}
\hline Aerothermal Entry Environments- Deployable & Value \\
\hline Peak Heat Rate (Aerocapture) & $110 \mathrm{~W} / \mathrm{cm}^{2}$ \\
\hline Peak Aerocapture Heat Rate (Convection) & $90 \mathrm{~W} / \mathrm{cm}^{2}$ \\
\hline Peak Aerocapture Heat Rate (Radiation) & $60 \mathrm{~W} / \mathrm{cm}^{2}$ \\
\hline Peak Heat Rate (Entry) & $30 \mathrm{~W} / \mathrm{cm}^{2}$ \\
\hline Peak Entry Heat Rate (Convection) & $30 \mathrm{~W} / \mathrm{cm}^{2}$ \\
\hline Peak Entry Heat Rate (Radiation) & $0 \mathrm{~W} / \mathrm{cm}^{2}$ \\
\hline Total Heat Load (Aerocapture + Entry) & $14 \mathrm{~kJ} / \mathrm{cm}^{2}$ \\
\hline Heat Load (Aerocapture) & $10 \mathrm{~kJ} / \mathrm{cm}^{2}$ \\
\hline Heat Load (Entry) & $4 \mathrm{~kJ} / \mathrm{cm}^{2}$ \\
\hline Peak Pressure (Aerocapture) & $14 \mathrm{kPa}$ \\
\hline Peak Pressure (Entry) & $10 \mathrm{kPa}$ \\
\hline Peak Shear Force (Aerocapture) & $90 \mathrm{~Pa}$ \\
\hline Peak Shear Force (Entry) & $60 \mathrm{~Pa}$ \\
\hline
\end{tabular}

Table 2: Summary of aerothermal environments for the $23 \mathrm{~m}$ diameter HIAD aeroshell concept. 
Increasing the diameter of the HIAD would decrease the heating environments experienced, obviating the need for a flexible ablator solution. However, there are many unknown risks to the utilization of such large structures, such as control authority, fluid structure interactions, and system complexity. While the development of insulating flexible materials is more advanced ${ }^{4}$, there are few, if any, flexible ablator concepts that could be utilized as deployable systems. Thus, the pursuit of flexible concepts that are similar to well known low density rigid ablatives such as PICA and Silicone Impregnated Reusable Ceramic Ablator (SIRCA) are conceptual extensions that could meet the packaging, deployment and aerothermal performance required for the HIAD concept. 


\section{Roadmap Development}

\section{A. Approach}

\section{$\underline{\text { Rigid Ablators }}$}

The goal of the Rigid ablator screening/development campaign is to mature two rigid ablator concepts to TRL 5 by 2013. Figure 5 shows a high-level depiction of the development methodology. Included are low TRL TPS concept on-ramps to provide a screening and down select pathway for more comprehensive aerothermal test and design. These small scale screening tests include utilizing the Laser Hardened Materials Evaluation Laboratory (LHMEL) located at the Air Force Research Laboratory as well as the Hypersonic Materials Environmental Test System (HyMETS) located at LaRC. The screening tests will show the relative differences in the material in-depth and surface response and potential failure modes. Promising candidates from these tests then feed into the primary test campaign which utilizes larger scale ground test facilities, such as the arc-heaters at ARC and JSC. The primary testing Phases (1-4) gradually lead to the down select of concepts which warrant further detailed development in Phase 3 and 4. The outcome of Phase 3 and 4 are off-ramps into a focused development program which includes higher fidelity material response model development, a key design tool used in TPS sizing. Once the response models and other acceptance criteria have been met, the material passes the TRL 5 gate.

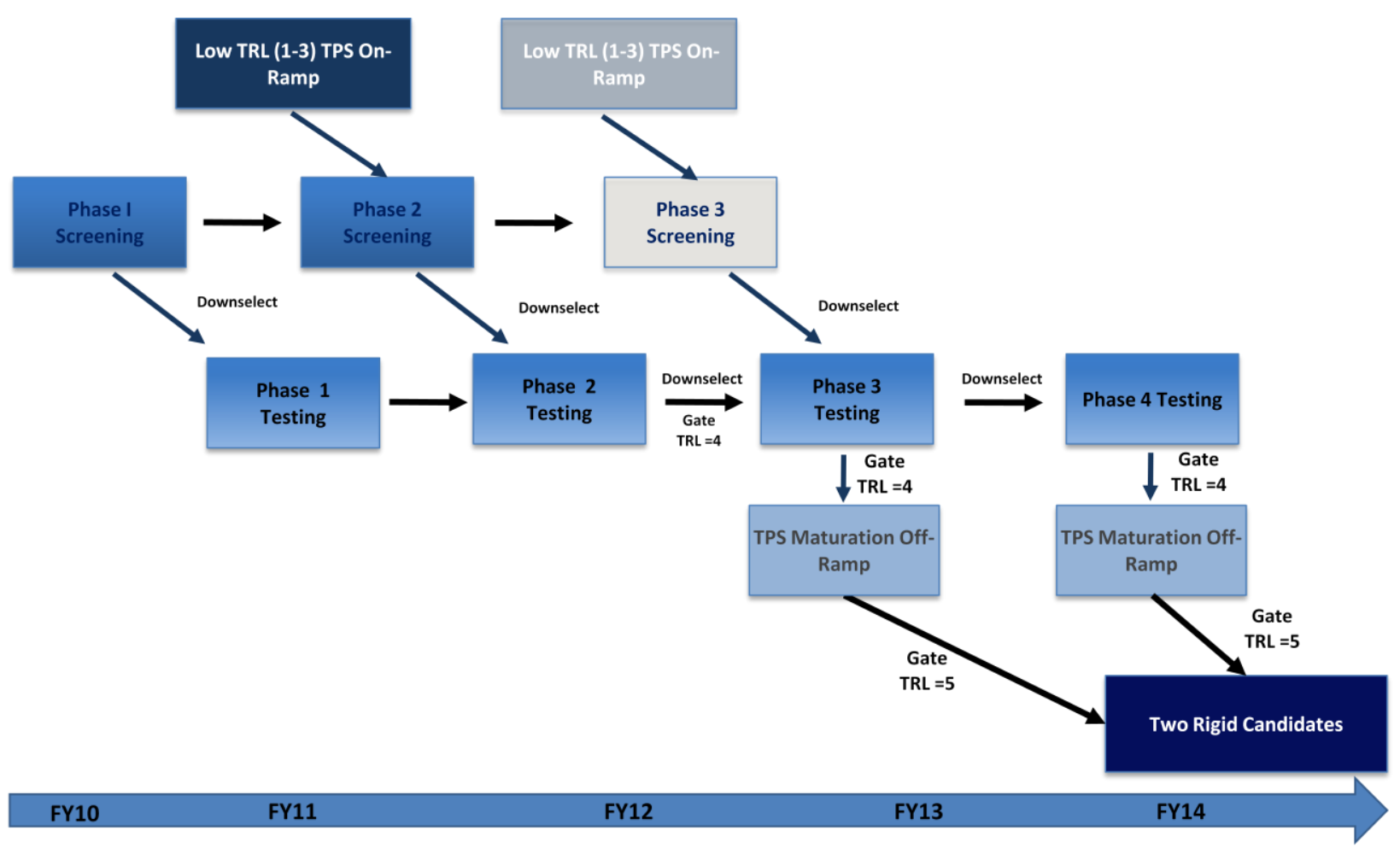

Figure 5: Rigid Ablator Technology Maturation Framework

\section{$\underline{\text { Flexible Ablators }}$}

Similar to the rigid ablator technology maturation framework, the EDL TDP will develop deployable/flexible ablator concepts through a mix of screening, testing and material response model development. The EDL TDP anticipates that as the system level requirements become better defined for deployable concepts, further refinements to the advancement criteria and level of maturity attainable within the constraints of the current project plan will be 
implemented. Utilizing a phased technology infusion, development and test framework, three families of deployable ablator systems will be advanced to a TRL 4 by 2014 (Figure 6). One of the key test methods to be developed for the flexible ablator maturation campaign is mechanical and structural screening and test. A series of mechanical tests to determine potential failure modes and performance degradation parameters will be developed to identify appropriate screening and structural testing methodology. The nature of these tests is still to be determined, but at a minimum, uniaxial testing will be performed to understand stress strain behavior as well as four-point bend tests for relatively stiff flexible candidates. For more pliant flexible materials a tear test and/or stiction test method may be developed. In addition, packaging studies are needed to understand long-term degradation and potential mitigation techniques. This campaign culminates in three flexible TPS families to a TRL 4 by 2014 .

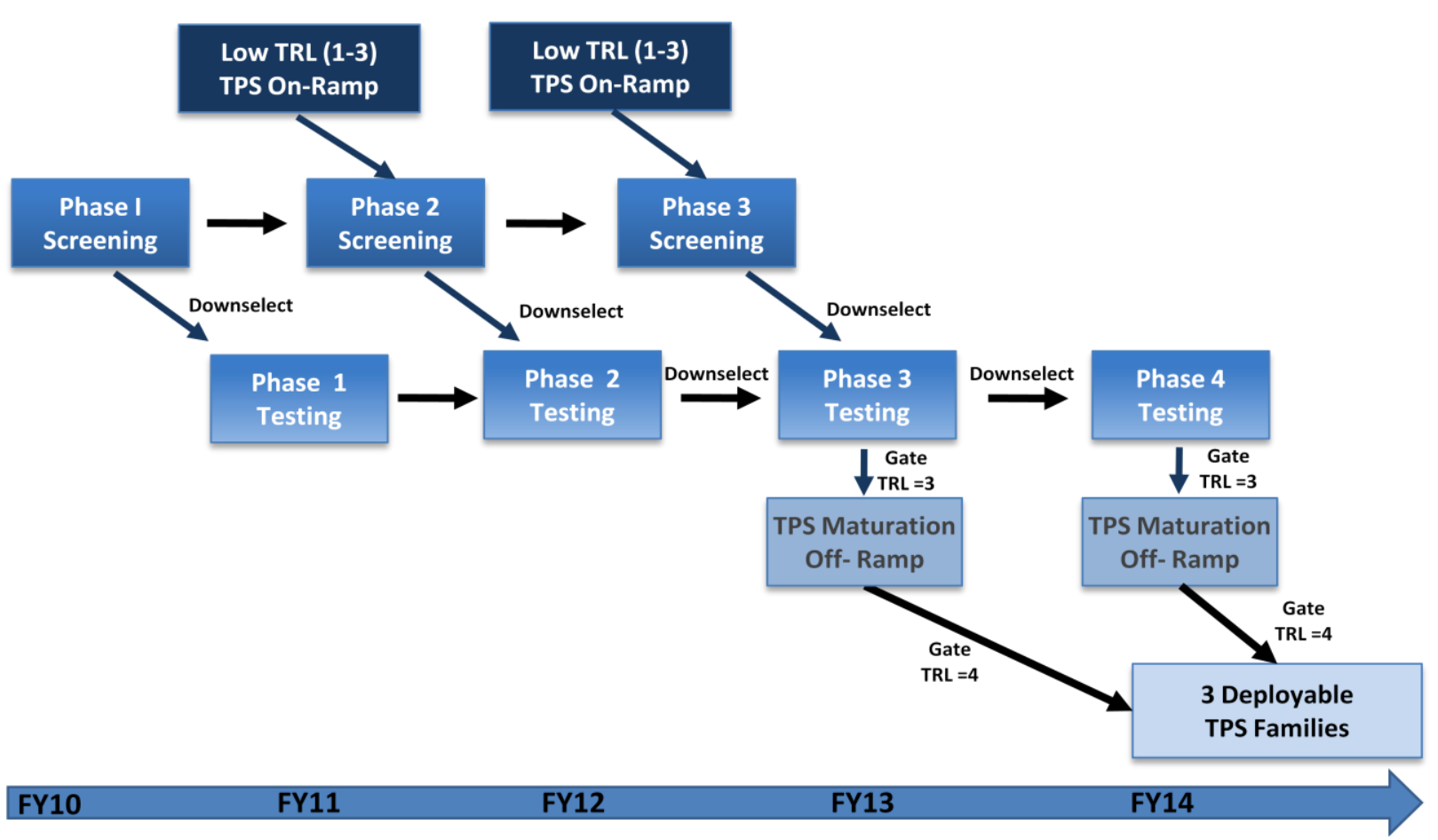

Figure 6: Flexible Ablator Technology Maturation Framework. 


\section{Evaluation Criteria}

A set of primarily qualitative evaluation criteria has been defined to aid in the down-selection process after each screening or test phase. This set of criteria, shown in Table 3, is used in addition to Key Performance Parameters (described later) and is important to the overall assessment of the eventual viability of the TPS technology for utilization on future human Mars Exploration Missions.

\begin{tabular}{|c|c|}
\hline Evaluation Criteria & Description \\
\hline Ablative Performance & $\begin{array}{l}\text { An evaluation of survivability, shape stability, and recession rates under relevant } \\
\text { aerothermal environment conditions }\end{array}$ \\
\hline Robustness & $\begin{array}{l}\text { An assessment of proven performance above and beyond mission requirements, } \\
\text { material tolerance to minor damage, and resilience against catastrophic failure due to } \\
\text { material complexities or sensitivities }\end{array}$ \\
\hline Reliability & An assessment of the number and likelihood of catastrophic failure modes \\
\hline Manufacturing Repeatability & $\begin{array}{l}\text { An assessment of the degree to which a material concept can be manufactured to a } \\
\text { tight performance specification; affects margin and flight lot acceptance costs }\end{array}$ \\
\hline Development Cost/Schedule Risk & $\begin{array}{l}\text { Qualitative assessment of cost/schedule risk during the development phase; complex } \\
\text { materials may be more costly and have longer development schedules }\end{array}$ \\
\hline Qualification Cost/Schedule Risk & $\begin{array}{l}\text { Qualitative assessment of cost/schedule risk during the qualification phase for a } \\
\text { mission application; complex materials may require additional characterization or } \\
\text { testing to meet mission reliability requirements }\end{array}$ \\
\hline $\begin{array}{l}\text { High-Fidelity Thermal Response } \\
\text { Model Development \& Validation } \\
\text { Cost/Schedule Risk }\end{array}$ & $\begin{array}{l}\text { Qualitative assessment of cost/schedule risk for the development and validation of a } \\
\text { high-fidelity thermal response model; material concepts that are complex, with many } \\
\text { layers or constituents, may complicate the model development and validation }\end{array}$ \\
\hline $\begin{array}{l}\text { High-Fidelity Thermostructural } \\
\text { Model Development \& Validation } \\
\text { Cost/Schedule Risk }\end{array}$ & $\begin{array}{l}\text { Qualitative assessment of cost/schedule risk for the development and validation of a } \\
\text { high-fidelity thermostructural model; material concepts that are complex, with many } \\
\text { layers or constituents, or are bonded to an intermediary material, may complicate the } \\
\text { model development and validation }\end{array}$ \\
\hline $\begin{array}{l}\text { Cost/Schedule Risk for Full-Scale } \\
\text { Manufacturing / Life Cycle Costs }\end{array}$ & $\begin{array}{l}\text { An assessment of the recurring costs and the cost/schedule risk associated with full- } \\
\text { scale manufacturing and integration onto an aeroshell; concepts that have complex } \\
\text { manufacturing steps, or those that require specialized materials, equipment, or require } \\
\text { multiple vendors, may have higher manufacturing costs and longer lead times }\end{array}$ \\
\hline Supplier Viability & $\begin{array}{l}\text { An assessment of the likelihood that a technology concept supplier will still be in } \\
\text { business and capable of manufacturing flight quality material decades from now }\end{array}$ \\
\hline
\end{tabular}

Table 3: Evaluation criteria to be used in the evaluation and downselect process

There is a combination of quantitative and qualitative evaluation criteria that will be used in the down selection process. Some criteria are more important than others in the early stages of the screening process, and this will be exploited through a scoring and weighting system. There are many alternatives for scoring and weighting these criteria and this system will be developed and optimized throughout the project. Sensitivity studies to weighting choices will also be performed. In the first year screening phase of the project, the down-selection process will likely be generous as the intent is to avoid elimination of promising candidates too early in the project. Therefore, evaluation criteria that are not weighted heavily during this first year screening phase will be assessed and tracked as the project progresses, and will become more important as the technology matures. The evaluation criteria and scoring system will evolve as the project progresses and as mission architectures and requirements become more mature. 


\section{B. Technology Readiness Levels}

Technology Readiness Levels (TRLs) are a useful metric that assess the maturity of a particular technology concept, and are commonly used by NASA and the DoD to allow the "consistent comparison of maturity between different types of technology." The metric is organized on a scale of 1 through 9, and a brief description of the level definitions is shown in Table 4. These high level definitions have been expanded into specific descriptions applicable to TPS technology development for implementation onto design reference architectures developed by the EDL SA. A technology must typically achieve TRL 6 before adoption into a flight project. For both rigid and flexible ablative TPS technologies, the development of specific TRL definitions were focused on TRLs 2 through 6 since technology concepts have been formulated. Each TRL description includes "achievement" criteria that details specific conditions that a technology concept must satisfy to achieve that particular TRL designation. The following paragraphs detail the initial set of specific definitions and achievement criteria of TRLs 2 through 6 for rigid and flexible ablative TPS concepts.

\begin{tabular}{|c|c|}
\hline $\begin{array}{c}\text { Technology } \\
\text { Readiness } \\
\text { Level }\end{array}$ & Summary \\
\hline TRL 1 & Basic principles observed and reported \\
\hline TRL 2 & Technology concept and/or application formulated \\
\hline TRL 3 & $\begin{array}{l}\text { Analytical and experimental critical function and/or } \\
\text { characteristic proof-of-concept }\end{array}$ \\
\hline TRL 4 & $\begin{array}{l}\text { Component and/or breadboard validation in a laboratory } \\
\text { environment }\end{array}$ \\
\hline TRL 5 & $\begin{array}{l}\text { Component and/or breadboard validation in relevant } \\
\text { environment }\end{array}$ \\
\hline TRL 6 & $\begin{array}{l}\text { System/subsystem model or prototype demonstration in a } \\
\text { relevant environment (ground or space) }\end{array}$ \\
\hline TRL 7 & System prototype demonstration in a space environment \\
\hline TRL 8 & $\begin{array}{l}\text { Actual system completed and "flight qualified" through test and } \\
\text { demonstration (ground or space) }\end{array}$ \\
\hline TRL 9 & $\begin{array}{l}\text { Actual system "flight proven" through successful mission } \\
\text { operations }\end{array}$ \\
\hline
\end{tabular}

Table 4: Standard TRL Definitions

\section{TRL 2}

\section{Technology concept and/or application formulated}

Once basic principles are observed in TRL 1, practical applications of these characteristics are identified. At this stage, formulation of the concept and initial fabrication of the materials are demonstrated. Achievement criteria for this TRL are that the technology concept and application to future human Mars mission architectures have been identified. In addition, initial fabrication of material concepts is demonstrated.

\section{TRL 3}

Analytical and experimental critical function and/or characteristic proof-of-concept 
At this step in the maturation process, active research and development is initiated. This includes both preliminary analytical studies to set the technology into an appropriate context and laboratory-based studies to empirically validate that the preliminary analytical predictions are trending with the results. These studies and experiments validate the benefits offered by the technology advancement to the applications and concepts formulated at TRL 2 .

Thermal screening tests in low cost facilities like LHMEL and HyMETS are performed at relevant conditions, and mechanical screening tests are initiated. For flexible ablators, bench top tests are performed to determine the minimum fold radius of curvature and tensile testing is performed at various temperatures. Structural four-point bend screening tests are performed on the rigid TPS materials.

Achievement criteria for this TRL include survival in thermal screening tests at flight-relevant heating conditions, and the identification of failure modes through mechanical testing. The basic constructs of analytical models have been established and are supported with basic material property characterization tests. For flexible ablator systems, potential functionality loss from exposure to extrinsic environmental effects, including vacuum, atomic oxygen, and thermal exposure are defined, and preliminary laboratory tests of survivability have been demonstrated. Feasibility of stowing the flexible ablator has been examined, stowage concepts have been identified, and critical issues have been addressed through basic laboratory-scale tests. Stowage and deployment requirements are developed and preliminary feasibility studies have been performed at sub-scale levels.

\section{TRL 4}

Component and/or breadboard validation in a laboratory environment

Following successful "proof of concept" at TRL 3, low fidelity validation is performed in environments consistent with requirements of eventual system applications. For both rigid and flexible ablator systems, sufficient material property data is generated to develop preliminary thermal and structural analytical response models.

Material ablative performance and thermal response data is obtained in a relevant environment utilizing arc jet facilities, which simulate the entry convective heating environment. Arc jet tests are performed at nominal heating rates expected for the dual-pulse entry environment at Mars. Preliminary mechanical tests are also performed, such as strain to failure, modulus, compression, shear, and tensile strength. Preliminary thermal property measurements, including coefficient of thermal expansion, char yield, specific heat, and elemental composition, are obtained for use in the development of the material thermal response models. For flexible ablators, fold and deployment tests are performed to determine the minimum radius of curvature for storage and to assess durability against loss of TPS functionality due to damage or shrinkage while in the stored state or during deployment.

Achievement criteria for this TRL include survival in flight-representative convective aerothermal environment tests, and the development of preliminary thermal and structural response models. An initial material property database is generated, and the material concept compositions are finalized. For the flexible ablators, stow and deployment tests have been completed to determine minimum standards for stowage and stowage volume, together with defined heatshield durability limits against loss of functionality due to the stowing process and mission storage duration. Potential issues of scalability have been identified, engineering solutions envisioned, and preliminary feasibility studies conducted.

\section{TRL 5}

\section{Component and/or breadboard validation in a relevant environment}

At this TRL, the fidelity of the component and the "relevant environment" in which the material concepts are tested increases significantly. The test article scale and test replicates become larger and the articles become more realistic in terms of application at the system level. At this TRL, predictive models replicate relevant environment tests and provide performance estimates for future relevant system level environmental tests.

Multiple test articles, ranging in sizes from approximately $10 \mathrm{~cm}$ to $50 \mathrm{~cm}$, are manufactured and include bonding to structural substrates using candidate bonding processes. Stagnation point and shear arc jet testing is performed at relevant heating rates, pressures, shear, and total heat loads. These arc jet test articles include sufficient in-depth instrumentation to support higher fidelity thermal model development. In addition, combined thermostructural tests 
(tensile and shear) are performed to obtain material performance data under combined heating and structural loading conditions. Thermal and structural tests of coupons with surface damage, repair techniques, and interface and gap designs are performed to further the development of features that would be required for a system application and scaling up to large sizes. Lastly, the material property database is expanded to include structural and thermal property data as a function of temperature.

Achievement criteria for TRL 5 include the development of mid-fidelity thermal and structural analytical response models and the identification of failure modes through thermal and structural tests. Preliminary structural analysis shows feasibility of scaling material concepts to sizes required for system applications. Robust gap/seam designs are demonstrated and initial Non-Destructive Evaluation (NDE) techniques are developed. In addition, satisfactory performance of surface damage, repair technique and interface/gap designs are demonstrated in a flight-relevant convective aerothermal and structural loading environment. For flexible ablators, large-scale manufacturability is demonstrated and relevant large-scale performance tests for stowage, deployment, and flight show adequate performance and functionality.

\section{TRL 6}

System/subsystem model or prototype demonstration in a relevant environment (ground or space)

A major step in the level of fidelity follows achievement of TRL 5. At TRL 6, a representative model or prototype system is ground tested in a relevant environment, over a range of conditions to which the technology would be exposed during qualification testing for a mission. While a well-designed ground test program will bound the conditions expected in flight, ground tests will rarely simulate all critical aspects of the flight environment, such as turbulence, boundary layer thickness, and combined convective and radiative heating. This inability to simulate the actual flight environment in ground tests results in significant uncertainties in ground test to flight traceability. These remaining uncertainties can only be addressed through flight tests.

For the ground test program, small-scale arc jet coupons are utilized for thermal response model validation in relevant convective aerothermal environment conditions. In addition, "special feature" coupons are manufactured to mimic subsystem level design features that interface with the TPS (e.g. structural attachment penetrations, flight TPS instrumentation). These coupons are tested in both aerothermal and thermostructural environments to verify the performance of these design features and to identify potential failure modes. The material property database is expanded further in order to sufficiently develop a high-fidelity thermal and structural response model. In addition, NDE techniques are validated at the coupon and prototype heatshield level. The prototype heatshield undergoes environmental tests representative of the launch and cruise phases of the mission (typically acoustic, vibration, and thermal vacuum). The data from these tests then validate the thermostructural analytical models. After successful completion of the qualification ground test program, this TRL culminates with a flight test that will demonstrate heatshield performance and provide data for model validation in a flight environment.

Achievement criteria for TRL 6 include the demonstration of large-scale manufacturability with established quality control processes, and the successful completion of environmental tests at the prototype heatshield level. Repair criteria and repair techniques are established and NDE techniques are validated. Failure modes are predicted and understood and sufficient data is gathered to support mission level reliability assessments. High fidelity thermal and structural analytical response models are developed and empirically validated first through a qualification ground test program, and finally through flight testing, where heatshield performance is demonstrated in a relevant flight environment. 


\section{Key Performance Parameters}

While TRLs summarized above are a fairly high level metric that measure the maturity of a technology, Key Performance Parameters (KPPs) are utilized to identify "those capabilities or characteristics (typically engineeringbased or related to safety or operational performance) considered most essential for successful mission accomplishment. Failure to meet a KPP threshold can be cause for the project, system, or advanced technology development to be reevaluated or terminated or for the system concept or the contributions of the individual systems to be reassessed." (NPR 7123.1 A) KPPs are required to be quantifiable, and two values are defined. A "threshold value" defines the minimum acceptable performance to successfully meet mission requirements, and the "goal value" defines the desired level of performance achievement for the technology. Both the threshold and goal values must exceed the state of the art to justify investment in the advancement of the particular technology. Threshold and goal values can be assigned at each TRL, and as the technology maturity advances from lower TRLs to TRL 6, performance attainment levels become more stringent. Tables 5 and 6 show the initial set of proposed KPPs (at TRL 6) for rigid ablators and deployable ablators, respectively. These KPPs will continually be reevaluated throughout the project lifecycle to ensure completeness of the set of performance parameters against which TPS technologies will be assessed.

\begin{tabular}{|c|c|c|c|c|c|}
\hline \multirow{2}{*}{$\begin{array}{c}\text { Key } \\
\text { Performance } \\
\text { Parameter }\end{array}$} & \multirow[b]{2}{*}{ KPP Category/Definition } & \multirow{2}{*}{$\begin{array}{c}\text { State of the Art } \\
\text { Value }\end{array}$} & \multicolumn{2}{|c|}{ TRL 6} & \multirow[b]{2}{*}{ Justification } \\
\hline & & & $\begin{array}{c}\text { Threshold } \\
\text { Value }\end{array}$ & Goal Value & \\
\hline KPPR-1 & $\begin{array}{l}\text { Areal Mass. A metric that will } \\
\text { allow for the evaluation of mass } \\
\text { savings over the current state of } \\
\text { the art. }\left(\mathrm{g} / \mathrm{cm}^{\wedge} 2\right)\end{array}$ & $\begin{array}{l}4.0 \\
\text { ( PICA 14-cm } \\
\text { thickness req) }\end{array}$ & $\begin{array}{c}3.0 \\
0.75 * \mathrm{PICA}\end{array}$ & $\begin{array}{c}2.0 \\
0.5^{*} \mathrm{PICA}\end{array}$ & $\begin{array}{c}\text { In order to develop a feasible } \\
\text { TPS, it must result in a reduced } \\
\text { mass from the baseline predicted } \\
\text { mass }\end{array}$ \\
\hline KPPR-2 & $\begin{array}{l}\text { Strain to Failure. A material } \\
\text { property metric that will } \\
\text { provide an indication of } \\
\text { compliance when bonded to an } \\
\text { underlying structure. } \\
\text { (microstrain) }\end{array}$ & $\begin{array}{r}3000 \\
\text { PICA }\end{array}$ & $\begin{array}{c}4500 \\
1.5 * \mathrm{PICA}\end{array}$ & $\begin{array}{c}\sim 30000 \\
1.5 * \text { AVCOAT }\end{array}$ & $\begin{array}{l}\text { Higher strain to failure allows for } \\
\text { direct bonding -- will need to } \\
\text { feed into aeroshell system } \\
\text { requirements }\end{array}$ \\
\hline KPPR-3 & $\begin{array}{l}\text { Manufacturing Scalability. A } \\
\text { metric that addresses an } \\
\text { assessment of the likelihood } \\
\text { that the technology concept will } \\
\text { successfully scale to the large } \\
\text { sizes required by the mission } \\
\text { architectures }\end{array}$ & $\begin{array}{c}20 " \mathrm{x} 40 " \\
\text { Max PICA tile size } \\
\text { 1-m Diam Cast } \\
\text { monolithic }\end{array}$ & $\begin{array}{l}2-\mathrm{m} \\
\text { diameter } \\
\text { by } 2-\mathrm{m} \\
\text { length }\end{array}$ & $\begin{array}{l}\text { 4-m diameter } \\
\text { by } 4-m \text { length }\end{array}$ & $\begin{array}{l}\text { Eventual application will be } \\
\text { large and will include many } \\
\text { features like seams in } \\
\text { honeycomb or between panels. } \\
\text { These manufactured sizes will } \\
\text { demonstrate all necessary } \\
\text { features and prove scalability to } \\
\text { the full size }\end{array}$ \\
\hline KPPR-4 & $\begin{array}{l}\text { Response Model Fidelity. } \\
\text { Ability to reliably and } \\
\text { repeatedly predict the thermal } \\
\text { response of the material to } \\
\text { applied environments. }\end{array}$ & $\begin{array}{l}\text { Mean: bias error } \\
30 \%, \text { time-to-peak } \\
\text { error } 30 \%, \\
\text { recession } 150 \%\end{array}$ & $\begin{array}{l}\text { Mean: bias } \\
\text { error } \\
<20 \% \text {, } \\
\text { time-to- } \\
\text { peak error } \\
<20 \% \text {, } \\
\text { recession } \\
\text { TBD }\end{array}$ & $\begin{array}{l}\text { Mean: bias } \\
\text { error }<10 \% \text {, } \\
\text { time-to-peak } \\
\text { error }<10 \% \text {, } \\
\text { recession } \\
\text { TBD }\end{array}$ & $\begin{array}{l}\text { Working from low to mid to high } \\
\text { fidelity models -- Need the } \\
\text { ability to predict response for } \\
\text { accurate design }\end{array}$ \\
\hline
\end{tabular}

Table 5: Rigid ablator Key Performance Parameters

\section{Rigid Ablator KPP Descriptions}

Since a reduction in overall TPS mass can directly translate into increased available payload mass, KPPR-1 is an areal mass metric that conveys mass savings over current state of the art TPS materials. The formulation of KPPR-1 threshold and goal values were derived from a conceptual design of a PICA ablator over an insulating tile. The initial TPS material sizing analysis for the dual layer concept showed that considerable mass savings could be realized by considering dual layer advanced ablative TPS materials concepts and technologies. ${ }^{3}$ KPPR-2 represents a strain to failure material property metric that characterizes the material compliance when bonded to an underlying structure. A higher strain to failure allows direct bonding to structural components, eliminating the need for strain isolation intermediary materials that increase overall TPS mass. 
Manufacturing scalability, KPPR-3, is an important aspect of TPS technology development. This KPP represents the ability of the concept to scale to the large physical sizes required for implementation onto an entry vehicle. It is not uncommon for a TPS material concept to experience manufacturing difficulties when scaling from small coupons to full-scale production sizes for large entry vehicles. In addition, scaling up to large dimensions often requires the development of robust gap and seam designs. Lastly, KPPR-4 describes the material response model fidelity, which is the ability to reliably and accurately predict the ablation and thermal response of the material to applied aerothermal environments. These response models are relied upon in the design and margin assessments of TPS materials utilized on flight vehicles, and are thus a critical performance parameter for TPS technology development.

\section{Flexible Ablator KPP Descriptions}

Since flexible ablator systems are currently at a conceptual level, no "state-of-the art" exists for these systems. Likewise for rigid ablators, areal mass (KPPF-1) is a critical performance parameter to express the mass savings possible over the currently defined state of the art. In order to define threshold and goal KPP values, SIRCA was utilized as the state of the art. SIRCA is a low-density rigid ablator that was used on the aftbody of the Mars Pathfinder and Mars Exploration Rover (MER) entry vehicles.

As with rigid ablator systems, full-scale manufacturability is a critical parameter, but there is also a significant added complexity factor for implementation onto a deployable system. KPPF-2 represents the capability of the flexible TPS material to be joined, closed-out, and assembled with the deploying system at full scale. Current state of the art for this parameter has been defined as Shuttle insulative AFRSI blankets. A "fold-ability" parameter has been defined for KPPF-3, and it will be measured by the minimum radius of curvature that can be obtained without degradation in TPS performance. The smaller the fold radius that the material can achieve, the smaller the volume it will require for stowage. Since minimizing the stowage volume required for the TPS maximizes the available payload volume, "stow-ability" has been defined as KPPF-4. This KPP represents the storage volume required for the deployable ablator and takes into account the time period of storage to ensure TPS performance and functionality has not been degraded.

Lastly, as with rigid ablator systems, material response fidelity is a critical performance parameter. KPPF-5 is similarly defined as the ability to reliably and accurately predict the thermal response of the material to applied aerothermal environments. 


\begin{tabular}{|c|c|c|c|c|c|}
\hline \multirow{2}{*}{$\begin{array}{c}\text { Key } \\
\text { Performance } \\
\text { Parameter }\end{array}$} & \multirow[b]{2}{*}{ KPP Category/Definition } & \multirow{2}{*}{$\begin{array}{c}\text { State of the Art } \\
\text { Value }\end{array}$} & \multicolumn{2}{|c|}{ TRL 6} & \multirow[b]{2}{*}{ Justification } \\
\hline & & & $\begin{array}{c}\text { Threshold } \\
\text { Value }\end{array}$ & Goal Value & \\
\hline KPPF-1 & $\begin{array}{l}\text { TPS Mass. A metric that allows } \\
\text { evaluation of mass savings over the } \\
\text { current state of the art. (g/cm²) or } \\
\text { comparisons of estimated TPS masses } \\
\text { for EDL SA HIADS using ablative to } \\
\text { purely insulative TPS. Metrics for } \\
\text { comparison are i) areal mass for state- } \\
\text { of -the art rigid SIRCA ablator and ii) } \\
\text { Estimated TPS for the HIAD using a } \\
\text { flexible ablator compared to that using } \\
\text { purely insulating TPS. }\end{array}$ & $\begin{array}{l}\text { SIRCA-15 V. } \\
\text { HIAD mass with } \\
\text { Ablator and HIAD } \\
\text { with insulating TPS }\end{array}$ & SIRCA- $15 * 0.80$ & $\begin{array}{l}\text { SIRCA- } 15 * 0.6 \\
\text { HIAD mass with } \\
\text { ablator equal to or } \\
\text { less than that for } \\
\text { HIAD with insulating } \\
\text { TPS }\end{array}$ & $\begin{array}{l}\text { In order to develop a } \\
\text { feasible TPS, it must } \\
\text { result in a reduced Mars } \\
\text { arrival mass for a given } \\
\text { payload delivered to the } \\
\text { surface, e.g., } 40 \mathrm{mt} .\end{array}$ \\
\hline KPPF-2 & $\begin{array}{l}\text { Manufacturability: Capability of the } \\
\text { TPS material to be joined, closed-out } \\
\text { and assembled with the deploying } \\
\text { system at full scale. Detailed TPS } \\
\text { materials, processing specifications and } \\
\text { acceptance criterion documented }\end{array}$ & None & $\mid \begin{array}{l}\text { Half scale } \\
\text { demonstrating } \\
\text { all processes }\end{array}$ & $\begin{array}{l}\text { EDU demonstration } \\
\text { at flight test scale }\end{array}$ & $\begin{array}{l}\text { HIAD large size will } \\
\text { require multiple pieces } \\
\text { of TPS materials that } \\
\text { must be robustly joined } \\
\text { and assembled for the } \\
\text { HIAD system }\end{array}$ \\
\hline KPPF-3 & $\begin{array}{l}\text { Foldability: Minimum radius of } \\
\text { curvature without loss of TPS } \\
\text { functionality after long term storage }\end{array}$ & None & $3 "$ & $2^{\prime \prime}$ & $\begin{array}{l}\text { The smaller the fold } \\
\text { radius that the material } \\
\text { can achieve, the smaller } \\
\text { the volume (see KPPF- } \\
\text { 4) it will require stowed } \\
\text { Functionality after } \\
\text { stowage will also be } \\
\text { required. }\end{array}$ \\
\hline KPPF-4 & $\begin{array}{l}\text { Stowability: Minimum stowage } \\
\text { volume and portion of the mission life } \\
\text { that the TPS can remain in the folded } \\
\text { state and not lose its functionality }\end{array}$ & None & \begin{tabular}{|l|} 
volume \\
associated with \\
3" fold and $1.5 "$ \\
thickness \\
\end{tabular} & $\begin{array}{l}\text { volume associated } \\
\text { with } 2 " \text { fold and } 1.5 " \\
\text { thickness }\end{array}$ & $\begin{array}{l}\text { Minimum stowage } \\
\text { volume allows for } \\
\text { maximum payload } \\
\text { volume }\end{array}$ \\
\hline KPPF-5 & $\begin{array}{l}\text { Response Model Fidelity. Ability to } \\
\text { reliably and repeatedly predict the } \\
\text { thermal response of the material to } \\
\text { applied environments. }\end{array}$ & $\begin{array}{l}\text { None; in-depth } \\
\text { instrumentation in } \\
\text { flexible TPS is } \\
\text { immature. KPPs } \\
\text { apply to } \\
\text { backface/interface } \\
\text { boundaries and } \\
\text { surface temps }\end{array}$ & $\begin{array}{l}\text { Mean: bias error } \\
<20 \% \text {, time-to- } \\
\text { peak error } \\
<20 \% \text {, recession } \\
\text { TBD }\end{array}$ & $\begin{array}{l}\text { Mean: bias error } \\
<10 \% \text {, time-to-peak } \\
\text { error }<10 \%, \\
\text { recession TBD }\end{array}$ & $\begin{array}{l}\text { Working from low to } \\
\text { mid to high fidelity } \\
\text { models -- Need the } \\
\text { ability to predict } \\
\text { response for accurate } \\
\text { design }\end{array}$ \\
\hline
\end{tabular}

Table 6: Deployable ablator Key Performance Parameters 


\section{Project Framework}

The rigid ablator development process is shown in Figure 7 and the flexible ablator development process is shown in Figure 8. A key ground rule and assumption for the development of both ablator systems is that all entry aerothermal environment and non-entry loading and environmental condition requirements are provided by EDLSA. In addition, evaluation of the performance of the ablator/structure system requires definition of the aeroshell structural component and loading conditions from a separate Aeroshell development task.

\section{$\underline{\text { Rigid Ablator Test Process }}$}

As shown in Figure 7 for rigid ablator systems, once entry environment requirements are provided, the test conditions for the Phase 1 material and structural screening tests are defined. The ablative and thermal performance data from these initial material screening tests feed into test planning activities for higher fidelity aerothermal environment testing. In addition, thermal data obtained in the screening tests may be used in the development of preliminary material thermal response models. Structural screening test data feeds into test planning activities for higher fidelity Phase 2 structural testing and the development of preliminary thermostructural models. After successful materials screening tests, material property characterization testing is performed (such as char yield, specific heat, and elemental composition) to develop a preliminary material thermal response model. At each subsequent phase of testing, the fidelity of the test environment and test articles increases and the resulting data is used to mature and validate the response models, thus advancing the TRL. In order to obtain high fidelity thermal response data, the development of TPS instrumentation, appropriate for each material concept, is required. This instrumentation is utilized in Phase 2 and Phase 3 aerothermal environment coupon testing, and in parallel, is developed for integration into an aeroshell system.

Since the TPS is an integral part of the eventual aeroshell system, demonstration of manufacturing scalability, bonding processes and the development of NDE techniques is critical for the achievement of TRL 6. Manufacturing Development Units (MDUs) are used to demonstrate large scale manufacturability and to develop bonding and NDE processes. Engineering Development Units (EDUs) are then manufactured with processes refined from the MDU and are then subjected to environmental tests, such as thermal vacuum testing, to verify the integrity and robustness of the TPS/structure system under flight-like environmental conditions. The results of these activities then feed into the development and qualification of the TPS for a flight test vehicle.

A flight test will rarely achieve all of the parameters of interest for the eventual mission application, thus a TPS flight test will be designed to demonstrate the performance of the system at Mars mission relevant conditions deemed most critical for TPS performance demonstration. Data obtained from the flight test will then be used to validate the material thermal response and thermostructural response models. 


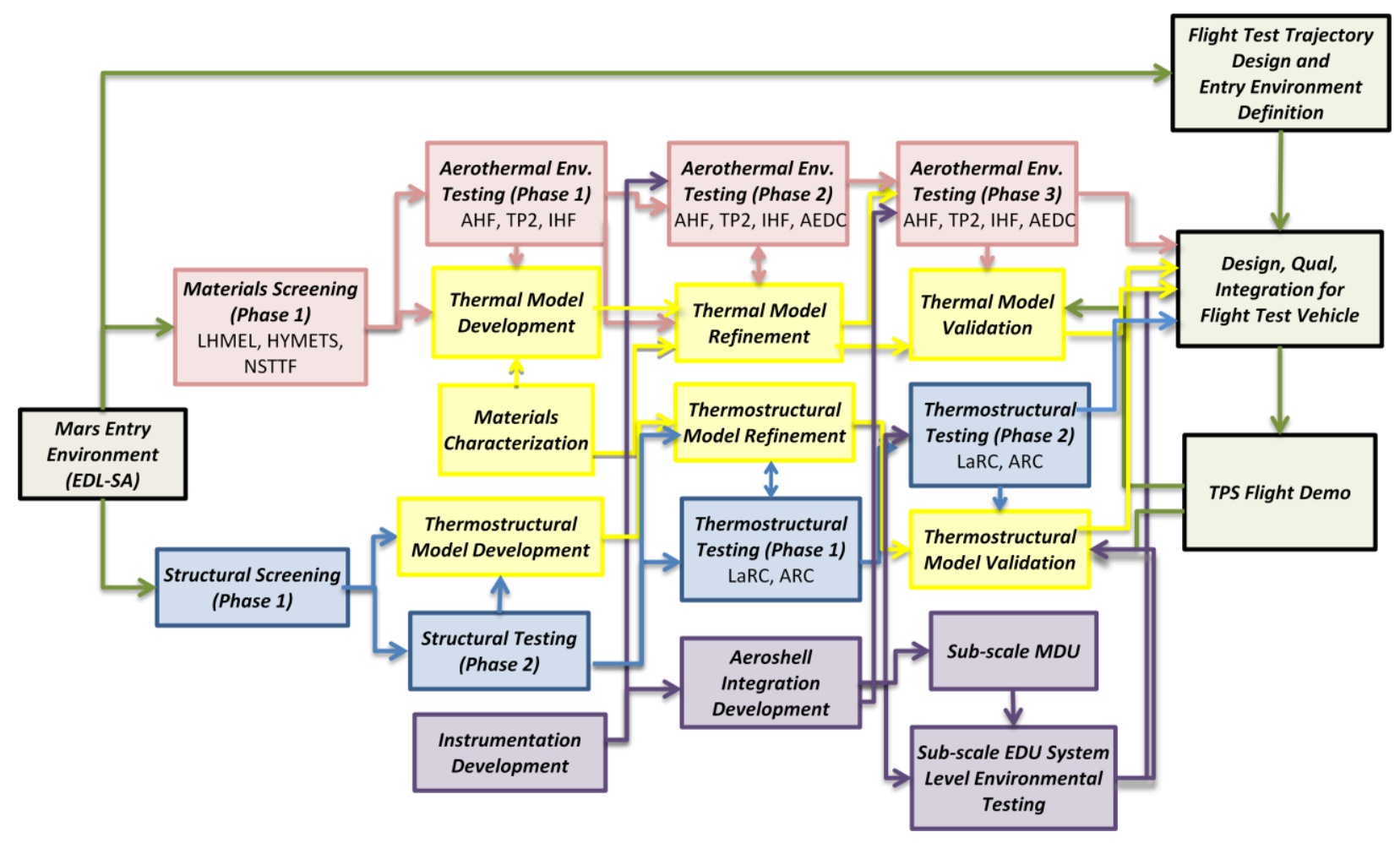

Figure 7: Development process for rigid ablators

\section{$\underline{\text { Flexible Ablator Development Process }}$}

Similar to the rigid ablator test program, flexible ablator screening test conditions are derived from entry environments defined by EDL SA or another systems analysis entity in the future. At each subsequent phase of testing, the fidelity of the test environment and test articles increases and the resulting data is used to mature and validate the material response models, thus advancing the TRL. Aeroelasticity tests are performed to evaluate the performance of the deployed flexible ablator system (at the coupon level) in an aerothermal environment, and EDUs are then manufactured for large scale inflation demonstration tests. Lastly, a sub-scale flight test is performed to demonstrate the performance of the deployed flexible ablator system in flight. 


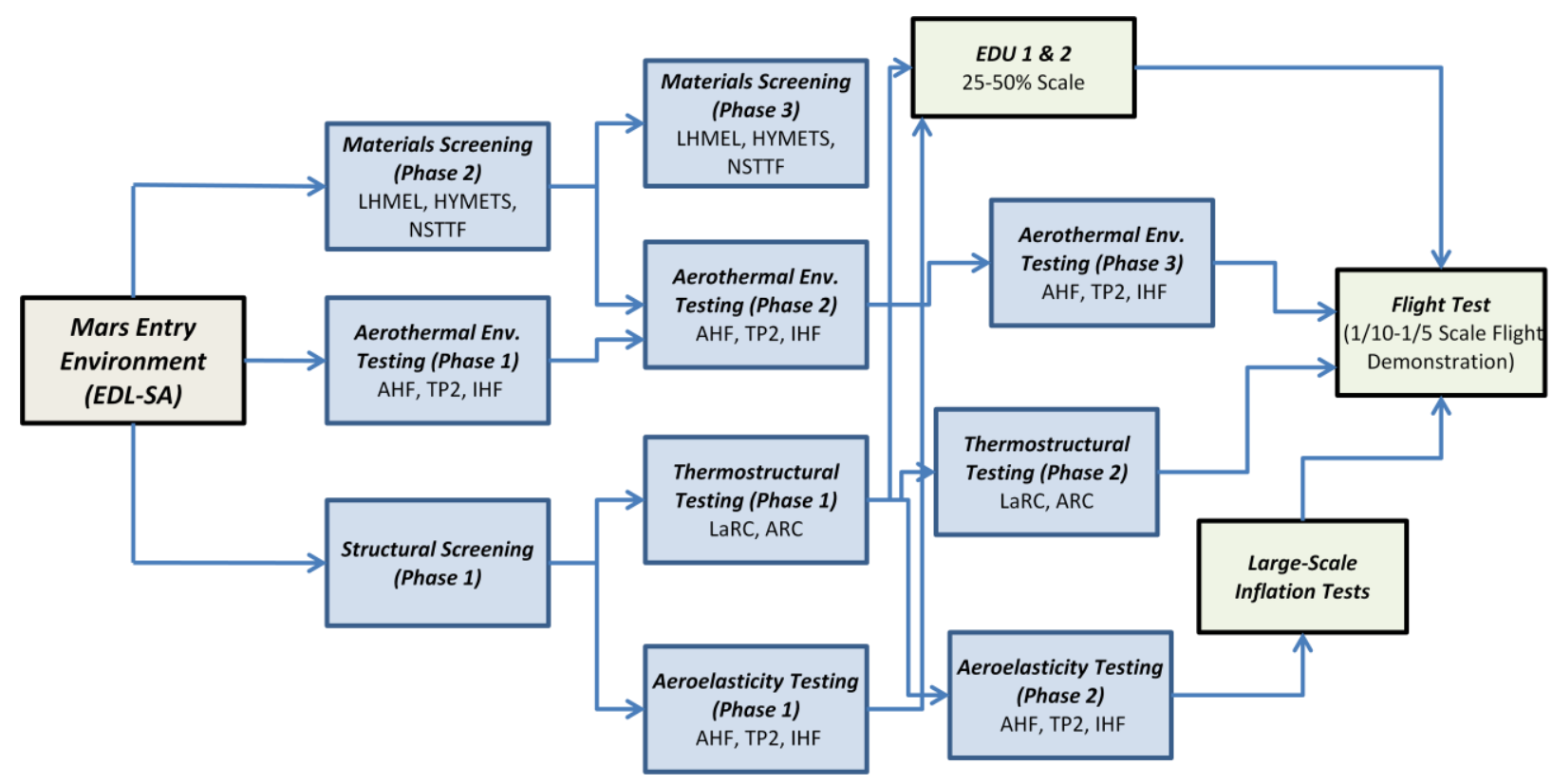

Figure 8: Development process for flexible ablators 


\section{E. Accelerated Roadmaps for the Development of Rigid and Flexible Ablators}

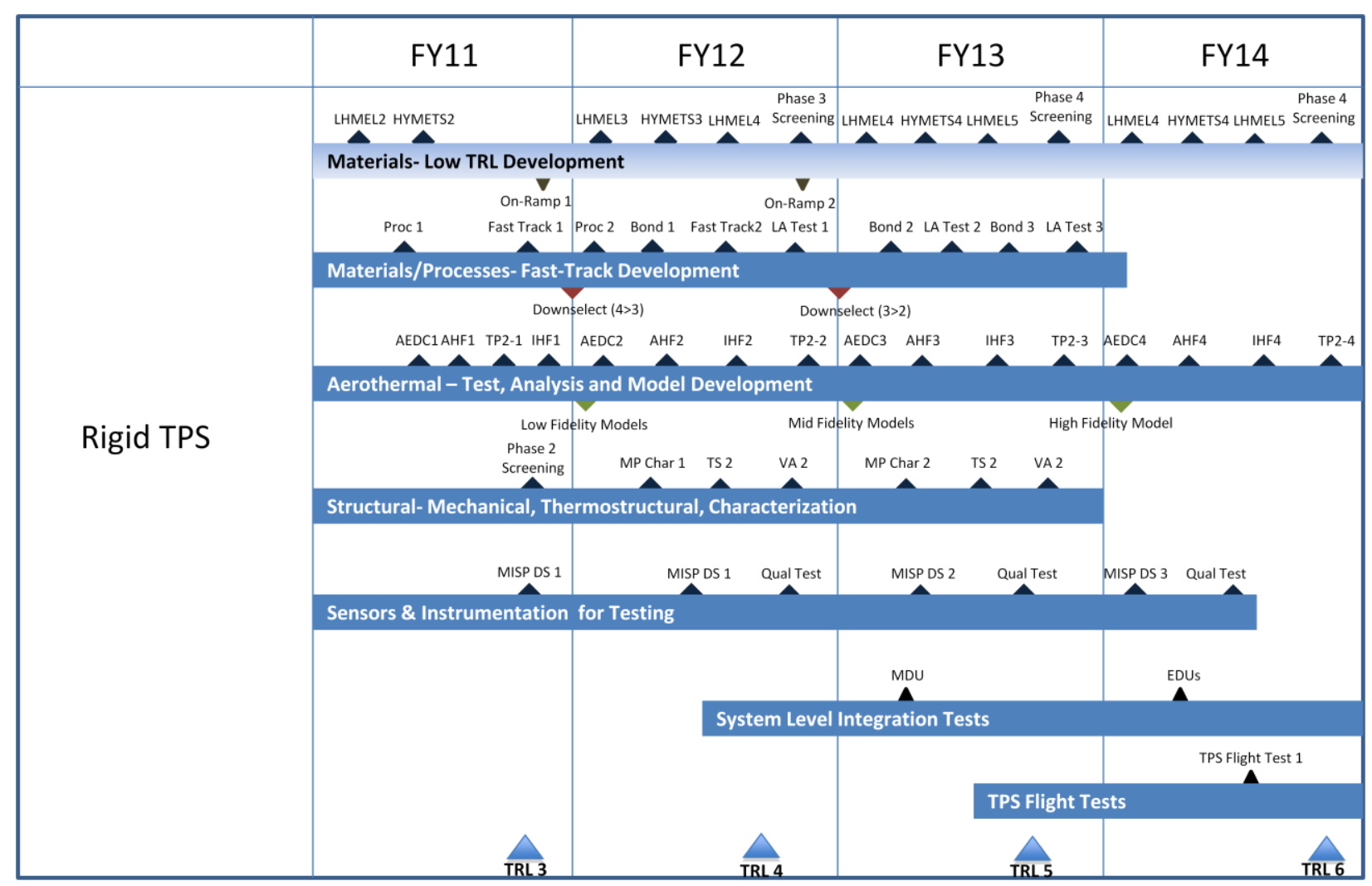

Figure 9: Accelerated technology development roadmaps to develop advanced rigid ablators for use on a potential Aerocapture Flagship mission in 2016

In response to the call for rapid maturation of technologies for Mars exploration, an accelerated technology development roadmap was constructed that culminates in flight tests in FY14 to mature a rigid ablator to TRL 6 by FY14. As shown in Figure 9, a comprehensive ground test and development program which includes material and process development, aerothermal test and model development, structural characterization, instrumentation and system level integration tests is laid out to rapidly mature a rigid ablator system for application to a potential Aerocapture Flagship mission. The progression through the various TRL gates is depicted across the bottom, and the processes described in the preceding sections will be applied to down select and mature the candidate technologies.

The foundation of the accelerated roadmap is Materials/Processes development. Similar to the technology maturation framework in Section IV A, a series of down selected materials from the screening tests will be fed into the Aerothermal Test, Analysis and Model Development task in order to build the tools necessary for robust material design. This task includes utilization of larger scale models instrumented for in depth thermal response characterization. The data from these tests is used for response model development culminating in a high fidelity material response model used for accurate TPS sizing. In parallel, the Structural Task will explore mechanical and thermostructural characterization to understand material performance and failure modes in order to predict how a material could be used at the appropriate scale for flight demonstration. The system level integration task will explore manufacturability, repeatability, and scalability through the fabrication of large scale $(>1 \mathrm{~m})$ articles, manufacturing design units (MDUs) and engineering design units (EDUs) at the scale appropriate for application to the flight demonstration mission. 


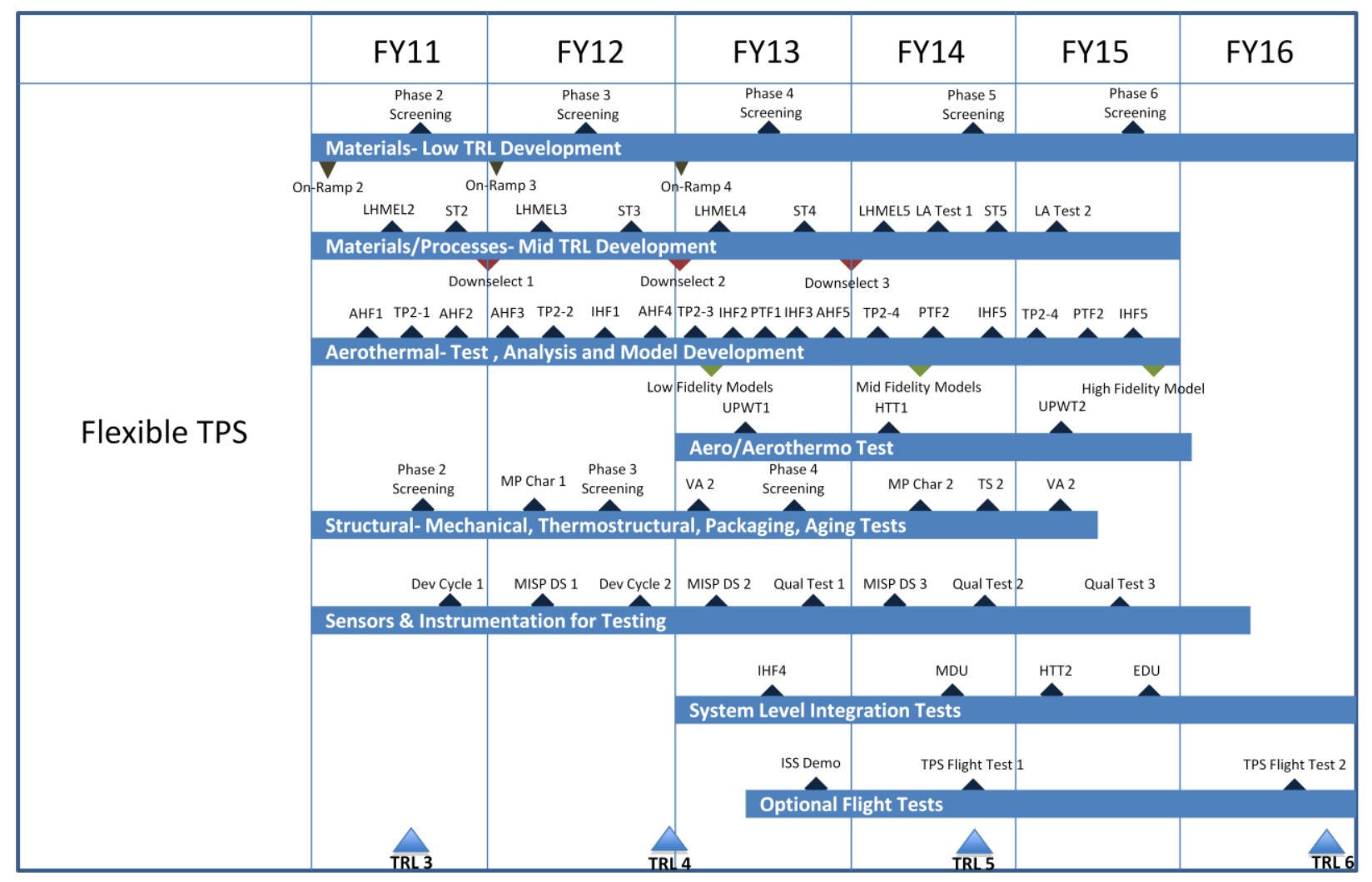

Figure 10: Flexible ablator accelerated roadmap for possible Flagship mission in 2018

In response to a call for rapid maturation of flexible TPS technologies for possible FY18 flight demonstration missions, an accelerated technology development Roadmap was constructed to result in materials reaching TRL 6 by FY16. The flexible ablators Roadmap is similar to rigid ablator roadmap in content with the addition of an Aerodynamics task that will provide aerodynamic test data and the requisite CFD validation codes. Other differences include more low TRL development activities aimed at maturing a wide variety of concepts through a series of screening tests. There are many unknowns in the development of flexible ablators and key technology advances could provide enhanced functionalities that are currently unidentified. The structural task will have additional studies aimed at developing packaging and aging tests to understand what, if any, performance degradation can be expected during long term stowage on a mission to Mars. The packaging tests will also aid in the design of the appropriate aerodynamic tests to understand how inflation dynamics and stability in hypersonic flows are impacted by different packaging techniques. Achievement of TRL 6 through a series of flight demonstration tests would have to occur in FY16 or earlier for potential use on a Flagship mission in 2018. 


\section{Summary}

The next generation EDL systems for Mars will require significant development to enable large Exploration Class Missions. TPS material development, in particular, will require significant efforts to improve the state of the art and to ensure that critical expertise and development capability is maintained for the Mars Exploration vision. The Roadmaps developed above detail two classes of TPS material technologies (rigid and flexible ablators) along with a detailed framework that describes the currently envisioned approach to rapidly mature these systems for flight demonstration missions within the next 3-5 years.

\section{References}

1. "Entry, Descent and Landing Systems Analysis (EDL-SA) for High Mass Exploration and Science Mars Mission Systems", Year 1 Report, December 2009

2. B.G. Drake (ed.), "Human Exploration of Mars Design Reference Architecture 5.0" NASA /SP-2009-566, July, 2009.

3. K. McGuire et al "Dual-Layer Thermal Protection System Sizing Studies for Mars Exploration" IPPW7 Abstract, submitted. 4. S.J. Hughes, J.S. Ware, J.A. Del Corso, R.A. Lugo "Deployable Aeroshell Flexible Thermal Protection System Testing" AIAA Aerodynamic Decelerator Systems Technology Conference, AIAA-2009-2926.

5. J.C. Mankins “Technology Readiness and Risk Assessments: A New Approach” Acta Astronautica, 65 (2009) 1208-1215. 